Research Paper:

\title{
Effect of Eight Weeks of Endurance Training and Stevia Supplemention on Atrial Natriuretic Peptide and $\beta$-Myosin Heavy Chain Expression Levels in Heart Tissue of Rats With Type 1 Diabetes
}

\author{
Kobra Soleymani ${ }^{1}$ (), *Asieh Abbassi Daloii ${ }^{1}$ (), Ali Reza Barari ${ }^{1}$ (), Ayoub Saeidi ${ }^{2}$ (1)
}

1. Department of Exercise Physiology, Ayatollah Amoli Branch, Islamic Azad University, Amol, Iran 2. Department of Exercise Physiology, Damghan Branch, Islamic Azad University, Damghan, Iran.

\begin{tabular}{|l|l|l|l}
\hline $\begin{array}{l}\text { Use vour devic to scan } \\
\text { and read the article online }\end{array}$ & $\begin{array}{l}\text { Citation Soleymani K, Abbassi Daloii A, Barari AR, Saeidi A. Effect of Eight Weeks of Endurance Training and Stevia Supplemention on } \\
\text { Atrial Natriuretic Peptide and } \beta \text {-Myosin Heavy Chain Expression Levels in Heart Tissue of Rats With Type 1 Diabetes. Journal of Inflam- } \\
\text { matory Diseases. 2020; 24(4):308-319. https://doi.org/10.32598/JQUMS.24.4.3 }\end{array}$ \\
dol https://doi.org/10.32598/JQUMS.24.4.3
\end{tabular}

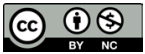

Received: 8 Jul 2020 Accepted: 24 Aug 2020 Available Online: 01 Oct 2020

Keywords:

Type 1 diabetes, Exercise, Stevia, Atrial natriuretic peptide, $\beta$-Myosin heavy chain, Heart tissue

\section{A B ST R A C T}

Background The effects of exercise and stevia extract on diabetes-related indicators have been already reported, but their cardiac benefits on Type 1 Diabetes (T1D) are unclear.

Objective This study aims to evaluate the effect of eight weeks of endurance training and stevia supplementation on gene expression levels of Atrial Natriuretic Peptide (ANP) and $\beta$-Myosin Heavy Chain $(\beta-\mathrm{MHC})$ in the heart tissue of T1D rats.

Methods In this experimental study, 25 rats with the average weight of 250-300 g were divided into five groups; healthy control, diabetic control, diabetic+supplementation, diabetic+training, and diabetic+trai ning+supplementation. T1D was induced by intraperitoneal injection of streptozotocin $(55 \mathrm{mg} / \mathrm{kg} / \mathrm{body}$ weight). Endurance training was performed 5 days a week at a speed of 20-30 meters per minute on a surface with a zero slope for 8 weeks. Stevia was gavaged in a dose of $250 \mathrm{mg} / \mathrm{kg} / \mathrm{body}$ weight. Rats were slaughtered 48 hours after the last training session. Cardiac tissue was used to measure the parameters. The gene expression of ANP and b-MHC in cardiac tissue was measured by real-time Polymerase Chain Reaction (PCR) method. Data were analyzed by using one-way ANOVA and Bonferroni post hoc test.

Findings The gene expression levels of ANP and $\beta-\mathrm{MHC}$ were significantly higher in the diabetic control group compared to the healthy control group $(P=0.001)$, and significantly lower in the diabetic+training and diabetic+training+supplementation groups compared to the diabetic control group $(P=0.001)$.

Conclusion Endurance training and stevia supplementation can have beneficial effects on the heart of T1D rats.

\section{Extended Abstract}

\section{Introduction}

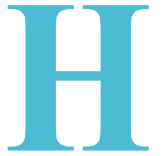

eart disease is one of the main complications of Type 1 Diabetes (T1D). In patients with T1D, Atrial Natriuretic Peptide (ANP) level is elevated associated with concomitant microalbuminuria, poor glycemic control, hypertension, and increased risk of cardiovascular diseases [5]. Myosins are a family of adenosine triphosphatedependent proteins that play a major role in skeletal and cardiac muscle contraction [9]. Two isoforms that are expressed in mammalian hearts are $\alpha$-Myosin Heavy Chain $(\alpha-\mathrm{MHC})$ and $\beta$-Myosin Heavy Chain ( $\beta$-MHC). Following stressors such as diabetes and high blood pressure, the

\section{* Corresponding Author:}

Asieh Abbassi Daloii

Address: Department of Physical Education and Sport Science, Ayatollah Amoli Branch, Islamic Azad University, Amol, Iran.

Tel: +98 (911) 1274366

E-Mail: abbasi.daloii@gmail.com 
alpha type is mainly converted to beta type. In people with heart failure, $\beta$-MHC expression is highly reduced [12].

The positive effects of regular exercise on various diseases, including T1D have been already reported [13]. Effects of cardiac protection following voluntary physical activity on myosin heavy chain gene in elderly rats have also been reported [14]. However, increased and decreased ANP gene expression in cardiac tissue was reported in male Wistar rats after 8 weeks of resistance training [15] and 6 weeks of low-intensity periodic training [16], respectively.

The Stevia rebaudiana herbal plant as a sweet food additive has many benefits for humans [17]. Stable effects with zero calories and the possibility of using it for diabetic patients are among the advantages of this plant [18]. Therefore, the use of this natural sweetener in food products, especially for people with diabetes, has become very important to be responsive to the desire in them to eat sweets [19].

Many studies have emphasized the effect of exercise therapy on diabetics who are at risk for cardiovascular disease [20, 21]. However, studies on the effect of aerobic exercises and herbal supplements on gene expression of factors affecting cardiac function are limited, especially in T1D subjects. Therefore, the present study aims to investigate the effect of eight weeks of endurance training and stevia supplementation on ANP and $\beta$-MHC gene expression in heart tissue of rats with T1D.

\section{Materials and Methods}

This is an experimental study conducted on 25 Wistar rats (weighting 250-300 g) prepared from the Islamic Azad University of Marvdasht Branch. They were divided into five groups; healthy control, diabetic control, diabetic + supplementation, diabetic + training, and diabetic + training+supplementation. Rats were given an intraperitoneal injection of streptozotocin $(55 \mathrm{mg} / \mathrm{kg} /$ body weight $)$ to induce diabetes. Endurance training was performed 5 days a week at a speed of 20-30 meters per minute on a surface with a zero slope for 8 weeks. Stevia was gavaged in a dose of $250 \mathrm{mg} / \mathrm{kg} /$ body weight [22]. Rats were slaughtered 48 hours after the last training session. Cardiac tissue was used to analyze the parameters. The gene expression of ANP and $\beta$-MHC in cardiac tissue was measured by real-time Polymerase Chain Reaction (PCR) method. Data were analyzed by one-way ANOVA and Bonferroni post hoc test considering a significance level of $\mathrm{P}<0.05$.

\section{Results}

The results showed that the gene expression of ANP and $\beta$-MHC in the heart tissue of diabetic control rats were significantly higher than in the healthy control group $(\mathrm{P}=0.001)$. Endurance training and the combination of endurance training and stevia supplementation significantly reduced ANP and $\beta$-MHC levels in cardiac tissue of diabetic rats compared to the diabetic controls $(\mathrm{P}=0.001)$.

\section{Discussion}

The ANP changes during exercise depends on the amount of dopamine, intensity and duration of activity, the amount of catecholamines, body condition during exercise, and hypoxic conditions [23-25]. The main reason for ANP level increase may be the stretched cardiac muscle due to increased atrial dimensions. During exercise, increase in the atrial dilatation may be due to central blood volume, in proportion to which atrial pressure increases ANP [26]. Therefore, exercise may reduce ANP level by modulating this pressure [27]. ANP levels in cardiac patients are high due to increased cardiac afterload. In the present study, endurance training reduced ANP gene expression in cardiac tissue of rats by reducing afterload. Regarding the mechanism of how endurance training affect $\beta$-MHC level in heart tissue, it has been shown that endurance training affect heart mass size and Pur and beta gene expression, and it seems that change in heart mass after endurance training is associated with MHC isoform expression [32].

Endurance training and the combination of endurance training and stevia supplementation may lead to significant reduction in $\beta$-MHC of T1D rats. Stevia has a variety of vitamins, especially vitamins $\mathrm{A}$ and $\mathrm{C}$, as well as many antioxidant elements such as selenium, cobalt and chromium. It also contains protein, fiber, carbohydrates, phosphorus, iron, calcium and sodium [31]. It is possible that the dose of stevia supplementation may affect the results such that clearer results can be obtained by changing its dosage. There were some limitations in the present study, including the lack of dopamine and the catecholamines measurement. Endurance training and stevia supplementation are recommended due to its possible beneficial effects on the heart of T1D rats.

\section{Ethical Considerations}

\section{Compliance with ethical guidelines}

This study obtained its ethical approval from the Research Ethics Committee of Islamic Azad University of Marvdasht Branch in Iran (Code: IR.IAU.M.REC.1399.015). 
Funding

This study was extracted from the $\mathrm{PhD}$. dissertation of the first author approved by the Department of Physical Education and Sport Science, Ayatollah Amoli Branch, Islamic Azad University, Amol.

Authors' contributions

Conceptualization, supervision, and methodology: Asieh Abbassi Daloii; Methodology, draft preparation, and data analysis: All authors; Editing \& review: Kobra Soleymani, Ali Reza Barari and Ayoub Saeidi.

Conflicts of interest

The authors declared no conflict of interest.

\section{Acknowledgments}

The authors would like to thank the participants and the Faculty of Physical Education and Sports Sciences at Islamic Azad University of Ayatollah Amoli Branch for their cooperation. 


\title{
تأثير هشت هفته تمرين استقامتى و مكمل استويا بر بيان ثن ANP و و و

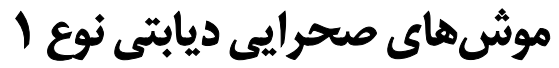

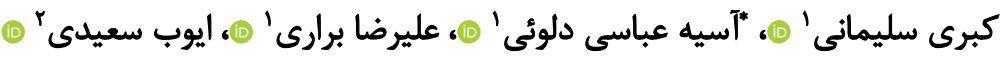

1. كروه فيزيولورثى ورزشى، واحد آمل آيت الله آملى، دانشعاه آزاد اسلامى، ايران.

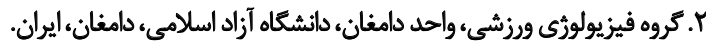

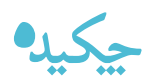

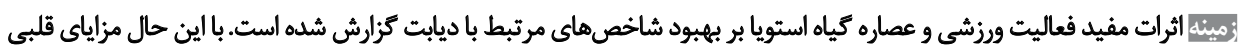

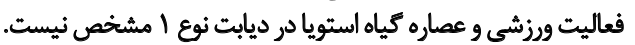

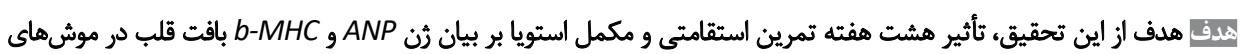

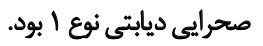

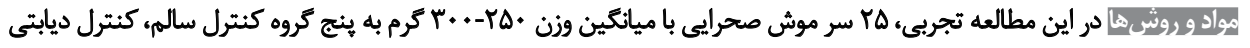

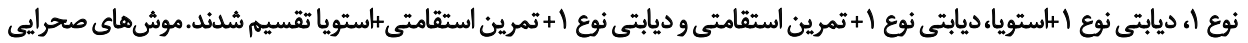

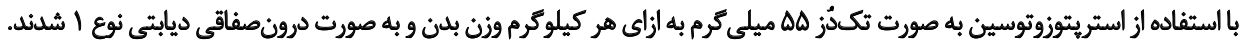

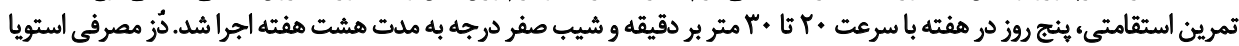

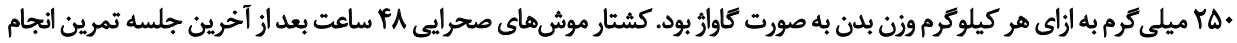

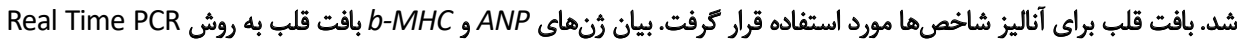

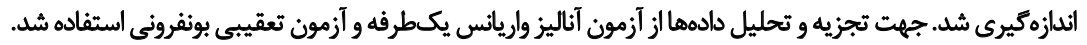

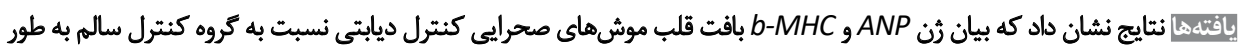

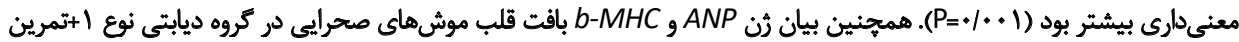

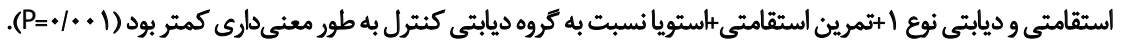

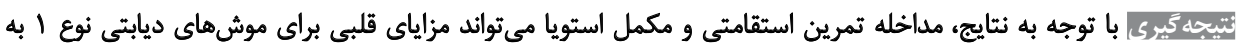
همراه داشتثله باشُشد.
\end{abstract}

\author{
تاريخ دريافت: 1 تير 99

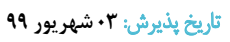

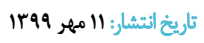

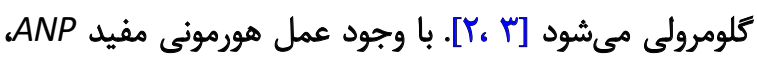

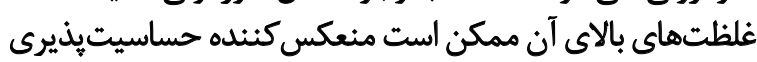

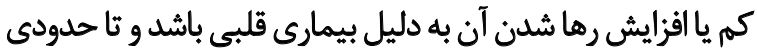

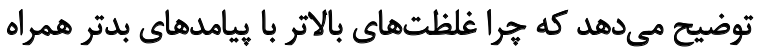

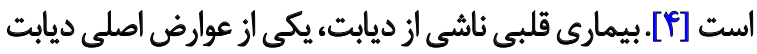

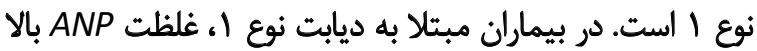

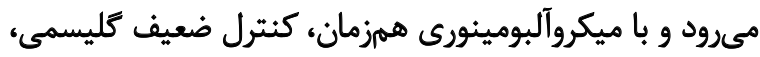

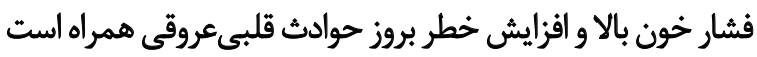

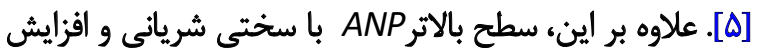

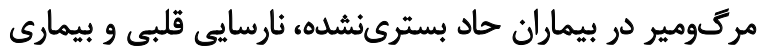

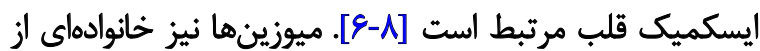

بيتيد دفعكننده سديم دهليزى' عمدتاً از ميوسيتهاي

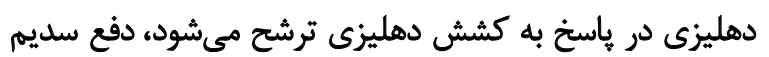

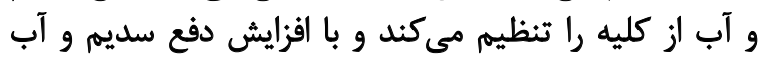

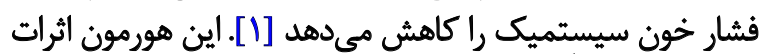

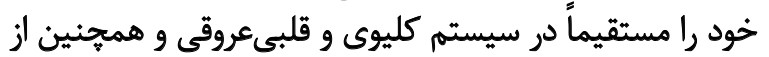

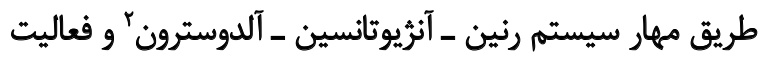

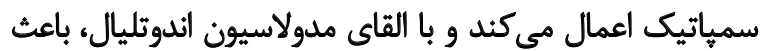
كشاد شدن عروق، افزايش جريان خون كليوى و فيلتراسيون

\section{Atrial Natriuretic Peptide (ANP)}

2. Renin - Angiotensin System (RAAS)

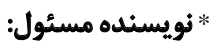

آسيه عباسى دلوئى نوينى نشانى: آمل، واحد آيتالله آملى، دانشعاه آزاد اسلامي، كروه فيزيولورئى ورزشى. تلفن: رايانامه: تلفن: abbasi.daloii@gmail.com 
استفاده از اين شيرين كننده طبيعى در محصولات غذايى بهوئ برئه

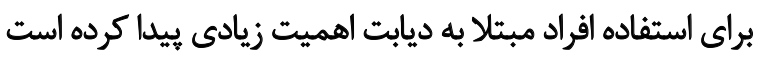

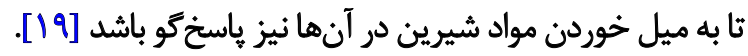
يافتن مكملهاى غذايي كه به بدن و از جمله بافت قلب در

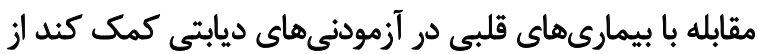

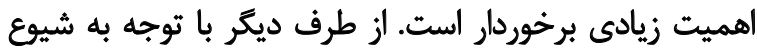

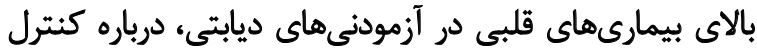

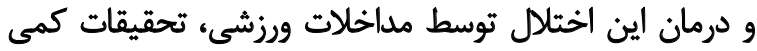

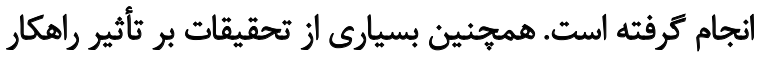

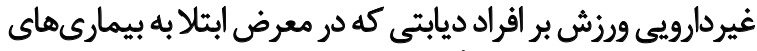

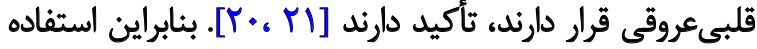

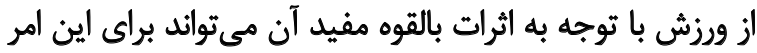

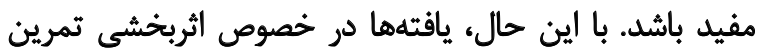

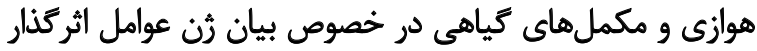

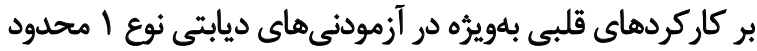

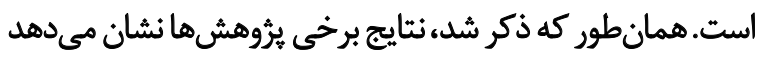

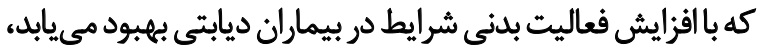

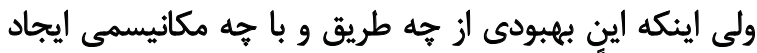

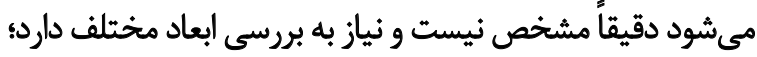

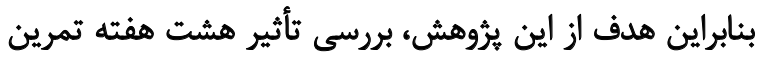

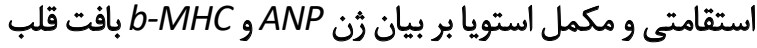
در موشهاى صحرايى ديابتى نوع استي است

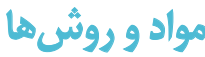

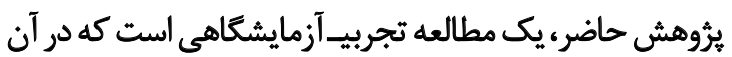

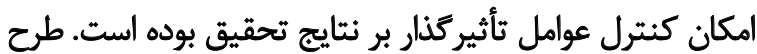

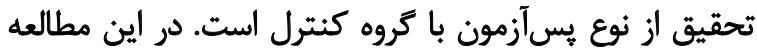

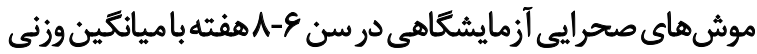

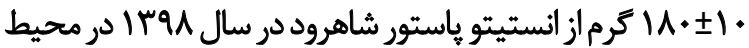

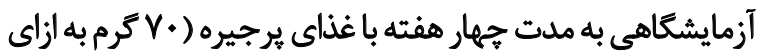

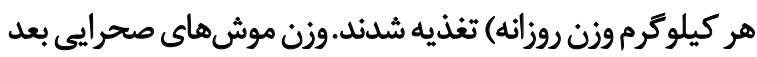

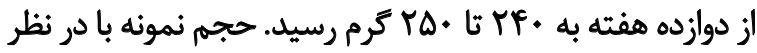

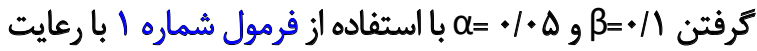

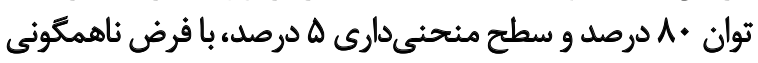

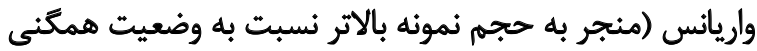

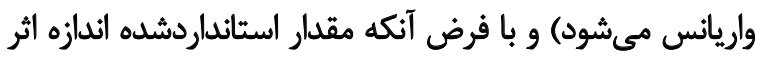

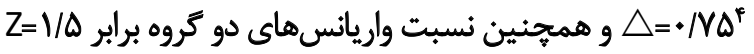

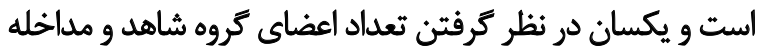

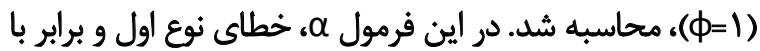

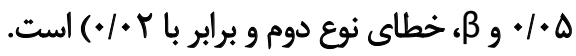

بروتئينهاى وابسته به آدنوزين ترى فُسفات" هستند كه در انقباض

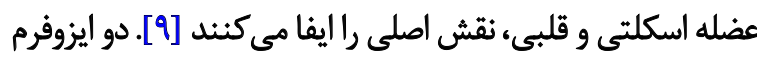

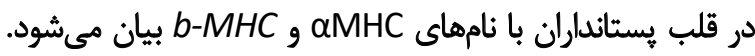

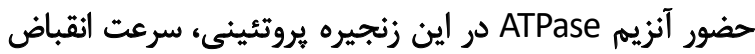

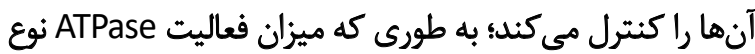

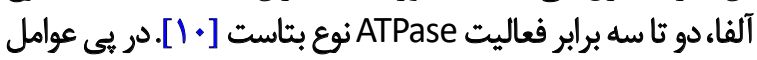

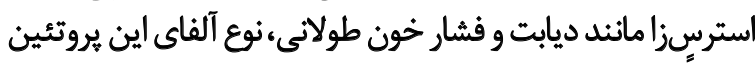

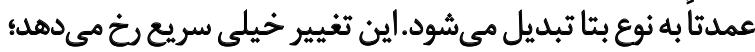

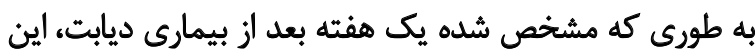

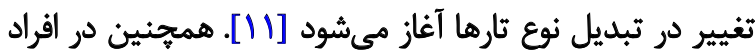

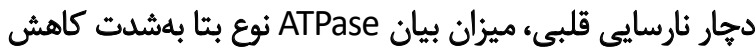

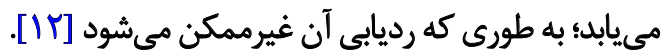

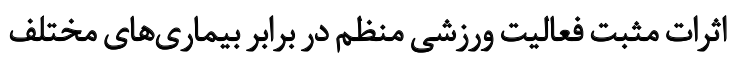

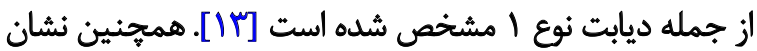

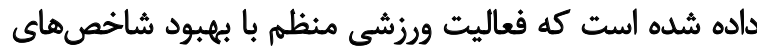

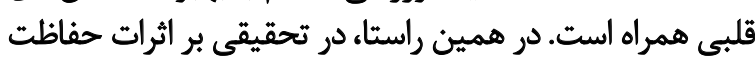

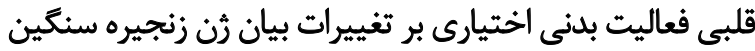

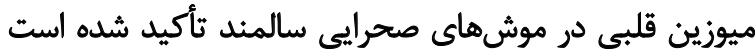

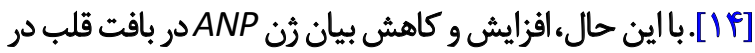

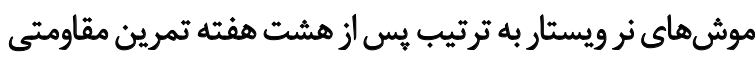

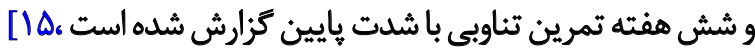

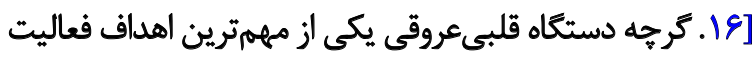

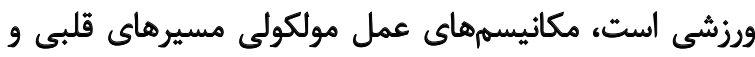
ورزش هوازى در قلب بيماران ديابتى ثاحد زئي زيادى ناشناخته باقيى

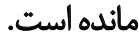
از طرفى، در سالهاى اخير تمايل زيادى به بررسى اثرات

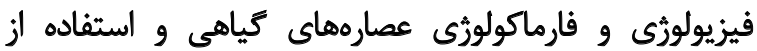

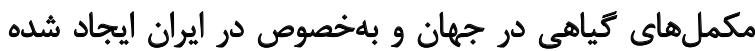

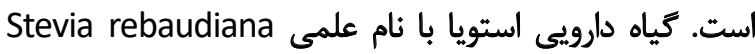

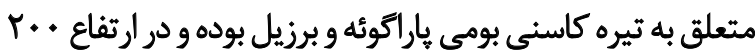

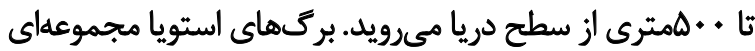

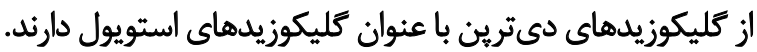

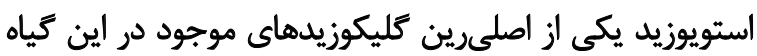

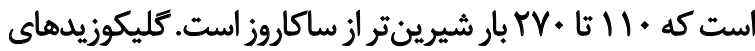

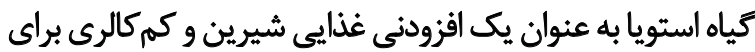

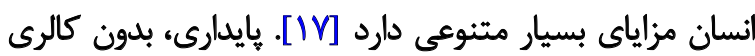

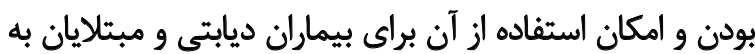

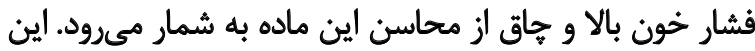

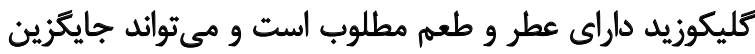

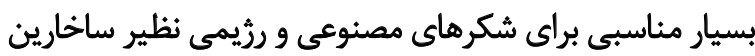

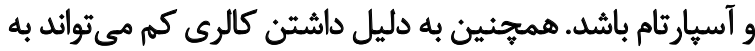
عنوان يك تركيب رزيمى به كار برده شود [1/ [1]. از اين رو امروزه

3. Adenosine Triphosphate (ATP) 


\begin{tabular}{|c|c|c|c|c|c|c|c|c|}
\hline هفته A & لهته Vف & هفته 7 & هفته ه & هفته & هنته & بفته r & آثناسازى ينجروزه (هفته () & زمان \\
\hline r. & r. & r. & ro & ra & r. & r. & 10 & سرعت (متر بر دقيقه) \\
\hline ro & ro & r. & r. & ra & ro & r. & r. & مدت (دقيقه) \\
\hline
\end{tabular}

كنترل نيز به ملت هشت هفته در قفس نكيهاري شديند و در

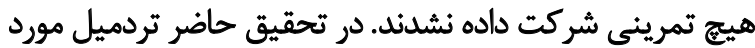

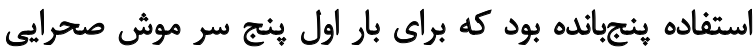

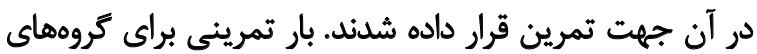

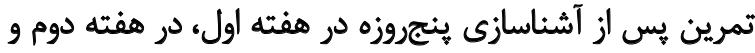

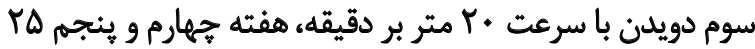

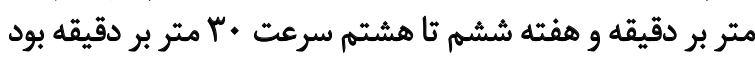

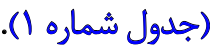

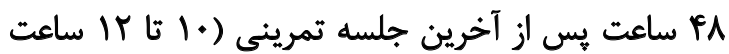

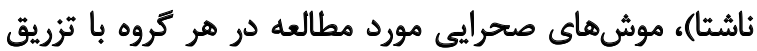

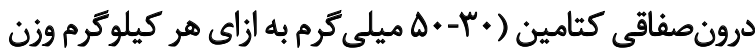

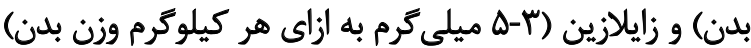

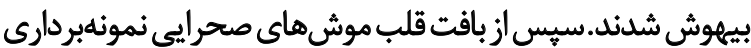

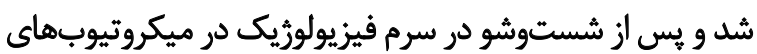

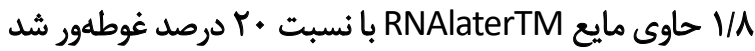
و جهت انجام آزمايشهاي رُنتيك به آزمايشكاه انتقال داده شد. اندازهكيرى بيان رنهاي فاكتورهاى موردنظر از بافت قلب به وسيله

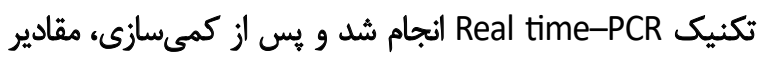

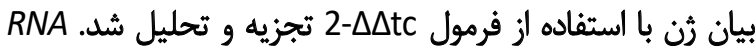

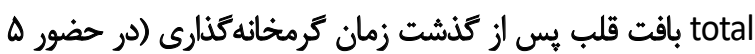

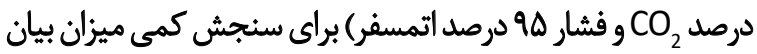

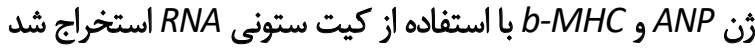

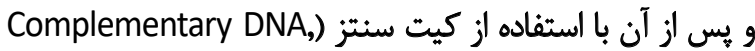

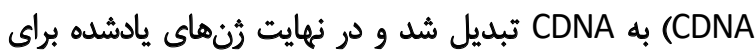
(quantitative Real-time PCR (qRT-, PCR SYBR و استفاده از (Applied Biosystems) PCR master mix Applied Biosystems, Sequence Detec-) در دستكاه Green شر tion Systems. Foster City, CA) ABI Step One

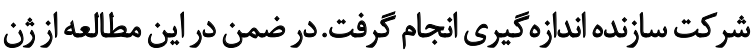

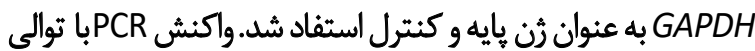
يرايمرهاي مورد استفاده در جدول شماره بـ ك ذكر شده است.

براى اطمينان از طبيعى بودن توزيع متغيرها، از آزمون شإييرو

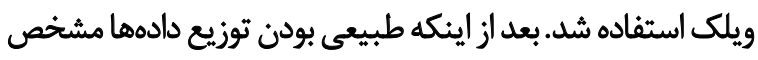

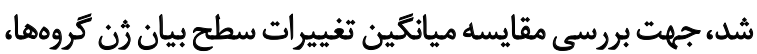

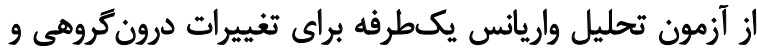
آزمون تعقيبى بونفرونى براى بررسى تفاوت بين تركيل بروهها استفاده

\section{$\left(\sigma_{1}^{2}+\sigma_{2}^{2}\right)(Z \alpha / 2+Z B)^{2}$}

$2 \Delta$ يس از تعيين حجم نمونه، كروهها به طور تصادفى به ينج

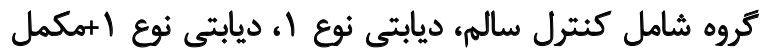

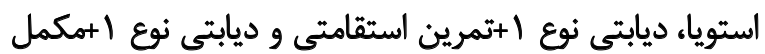

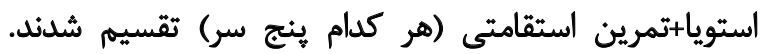

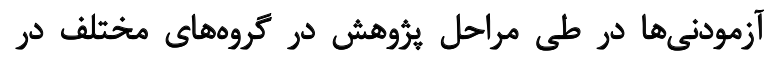

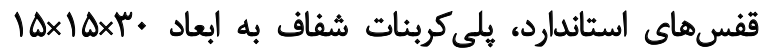

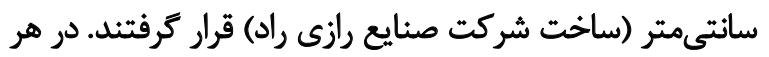

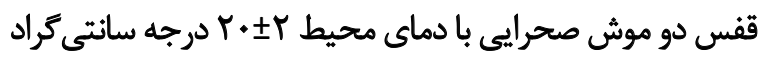

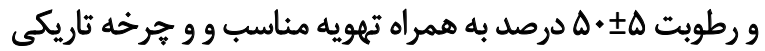

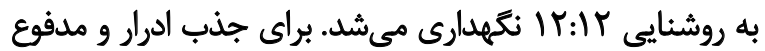

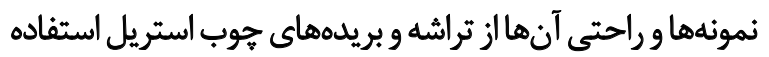

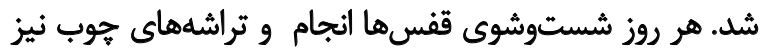

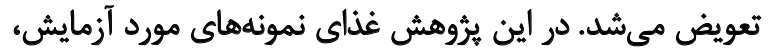

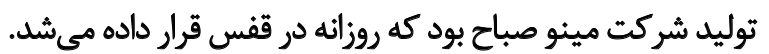

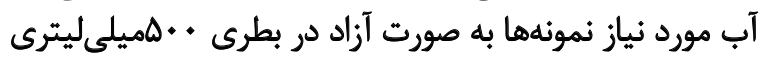

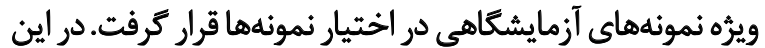

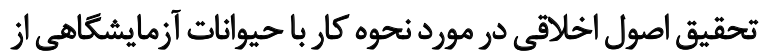

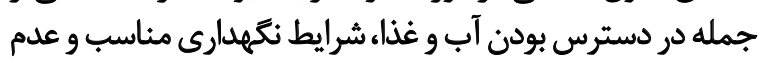

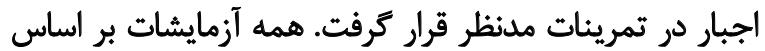
خطمشى هاى قرارداد هلسينكى اجرا شدر.

جهت ديابتى كردن موشهاي صحرايى مقدار استريتوزوتوسين

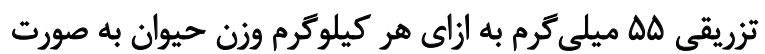

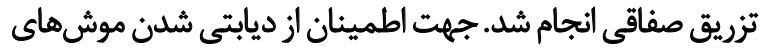

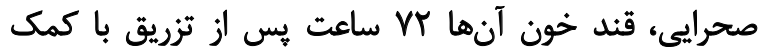

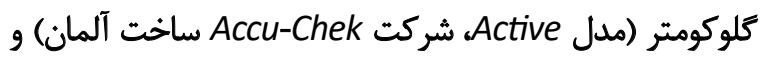

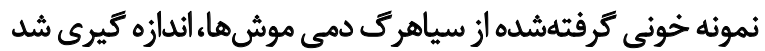

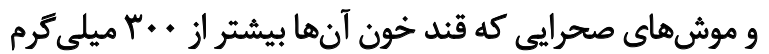

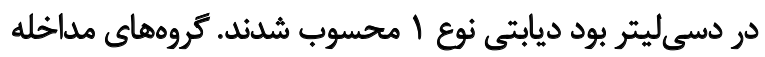

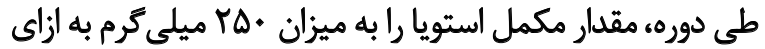

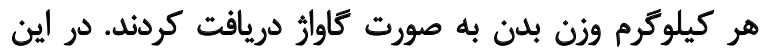

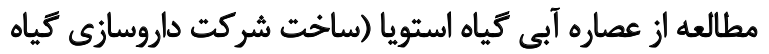

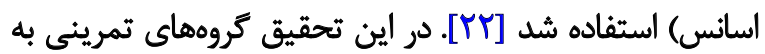

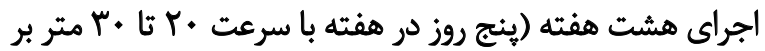
دقيقه و شيب صفر درجه) تمرين هوازى يرداختند و كروههاي 
جدول r. توالى برايمرهاي مورد استفاده

\begin{tabular}{|c|c|c|c|}
\hline 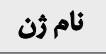 & يرايمرها & توالى & طول Amplicon \\
\hline$A N P$ & $\begin{array}{l}\text { Forward } \\
\text { Reverse }\end{array}$ & $\begin{array}{l}\text { GAGGAGAAGATGCCGGTAG } \\
\text { CTAGAGAGGGAGCTAAGTG }\end{array}$ & bp 1.f \\
\hline$b M H C$ & $\begin{array}{l}\text { Forward } \\
\text { Reverse }\end{array}$ & $\begin{array}{l}\text { TGAAGCTTACCCAGGAGAGCATCATGG } \\
\text { AAGAATTCTTGGAGAACTGTTGGTCC }\end{array}$ & bp 1.f \\
\hline GAPDH & $\begin{array}{l}\text { Forward } \\
\text { Reverse }\end{array}$ & $\begin{array}{l}\text { CAAGTTCAAGGGCACAGTCA } \\
\text { CCCCATTTGATGTTAGCGGG }\end{array}$ & bp 1.f \\
\hline
\end{tabular}

جدول "ا. ميانكين و انحراف معيار وزن موشهاي صحرايي در كروهاي مختلف

\begin{tabular}{|c|c|c|c|c|c|}
\hline \multicolumn{5}{|c|}{ ميانكين \ انحراف معيار } & \multirow{2}{*}{ متغير } \\
\hline ديابتى+تمرين+استويا & ديابتى+تمرين & استويا & كتترل ديابتى & كتترل سالم & \\
\hline$r \Delta \cdot / \& \pm r / \cdot \Lambda$ & $\pi q / q \pm e / \pi r$ & rAT/AET/T & YAT/Y $\pm F / 1$ & $r e q / \pm r / s$ & وزن اوليه (كرم) \\
\hline $\mid \& N \cdot \pm E / R$ & $194 / m \pm 4 / 88$ & $\mid E T / \Delta \pm 1 / 1$ & $I r N \cdot \pm r / I T$ & $r q T / T \pm T / V$ & وزن نهايى (كرم) \\
\hline
\end{tabular}

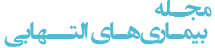

جدول ع. ميانكين و انحراف معيار متغيرهاى تحقيق در تروهاى مختلف

\begin{tabular}{|c|c|c|c|c|c|c|}
\hline ديابتى ورزشى استويا & ديابتى ورزشى & استويا & كنترل ديابتى & كثترل سالم & & مثغير \\
\hline V/ret./N & $V(\Delta) \pm * / 1$ & $|/| M \pm+1 \cdot 9$ & $r / 11 \pm .1 \cdot 9$ & $\pm \pm \%$ & ميانكين ثانحراف معيار & ANP \\
\hline$r q$ & DI & $n$ & 111 & - & & $(\Delta \Delta \mathrm{CT})$ \\
\hline
\end{tabular}

\begin{tabular}{|c|c|c|c|c|c|c|}
\hline$Y / \cdot I \pm \cdot / T Y$ & $r / m 9 \pm 1 / 19$ & $r / 99 \pm 1 / \%$ & $r / R T \pm=109$ & $1 \pm \%$ & ميانكين ثلانحراف معيار & b-MHC \\
\hline 1.1 & 119 & 199 & MT & - & درصد تغييرات & $(\Delta \Delta \mathrm{CT})$ \\
\hline
\end{tabular}

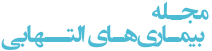

كنترل ديابتى نسبت به كروه كنترل سالم به طور معنى دارى

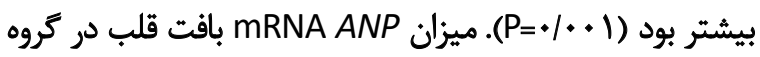

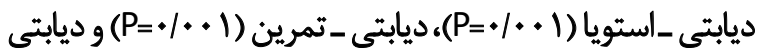

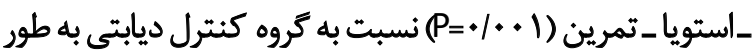

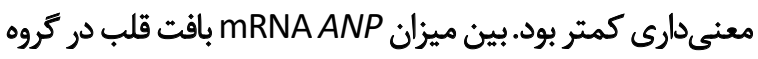

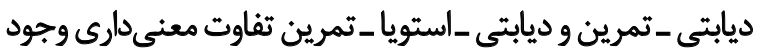

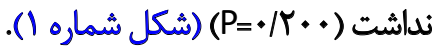

mRNA b-MHC تجزيه و تحليل دادهها نشان داد كه بين ميانكين

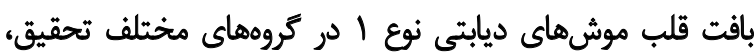

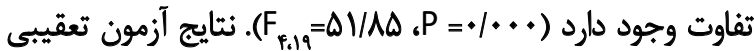

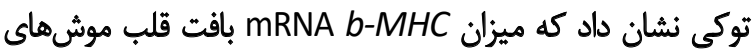

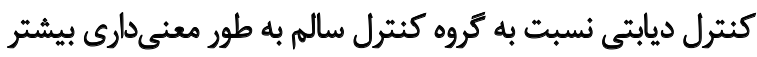

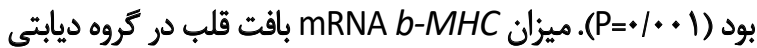

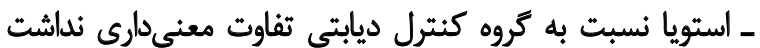

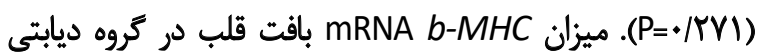

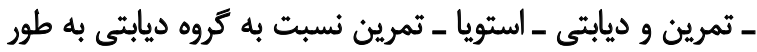

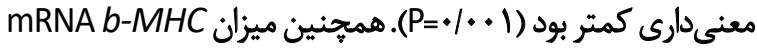

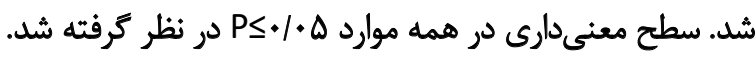

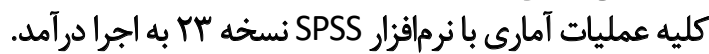

Latịl

ميانغين و انحراف معيار وزن موشهاى صحرايى كروههاى

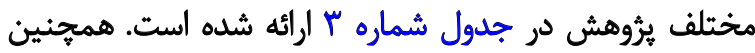
ميانكين، انحراف معيار و درصد تغييرات mRNA و mRNA ANP b-MHC

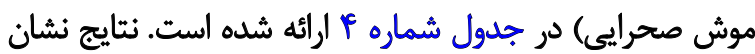

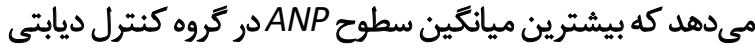

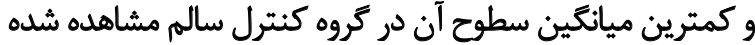

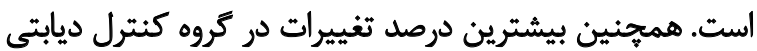

نسبت به كروه كنترل سالم به دست آمد (جدول شماره س). تجزيه و تحليل دادهها نشان داد كه بين ميانكين mRNAANP

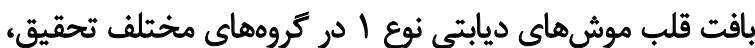

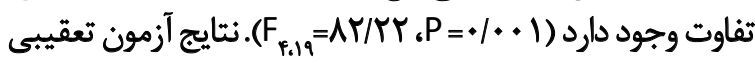
توكى نشان داد كه ميزان mRNA ANP بافت قلب موشهاي 


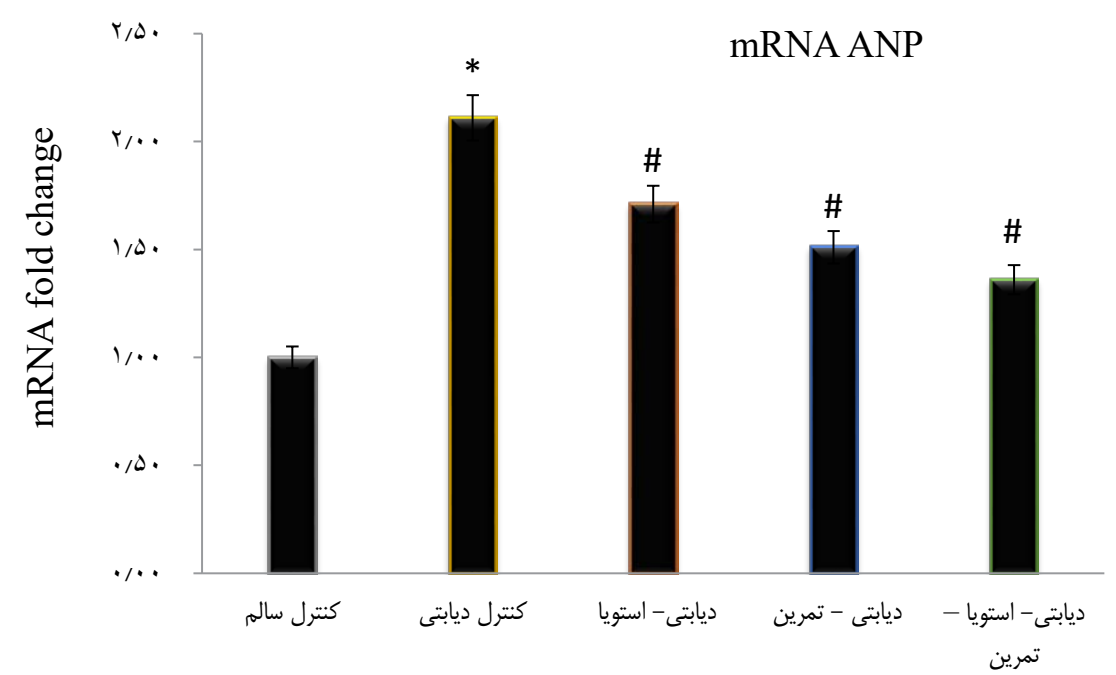

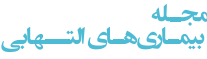

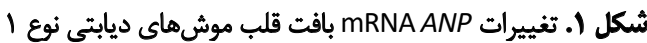

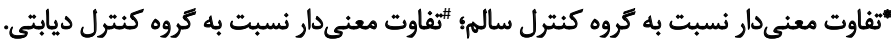

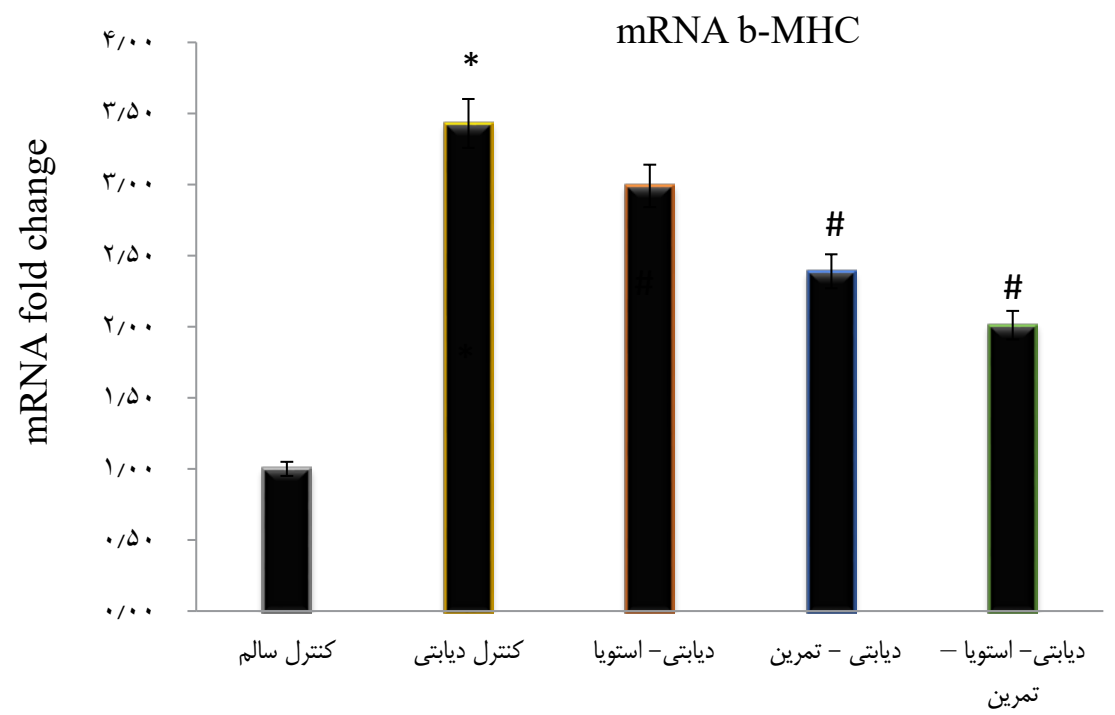

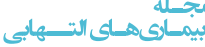

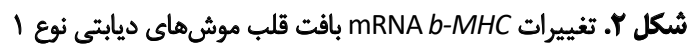

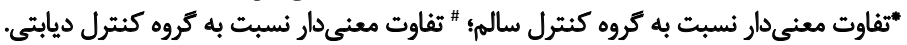

به بررسى هاى ما يُوهشهاى اندكى درباره اثر فعاليت ورزشى بر بر

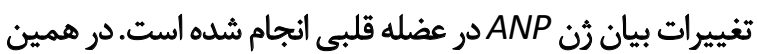

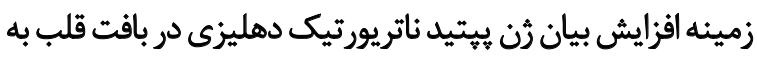

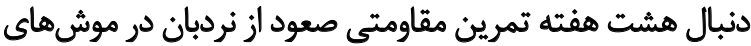

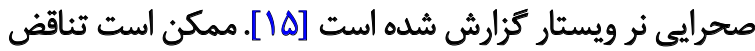

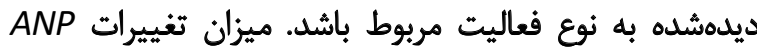

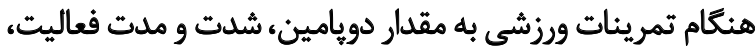

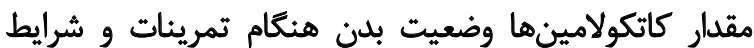

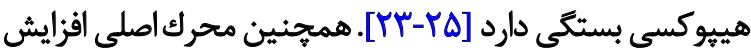

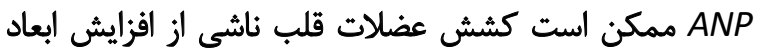

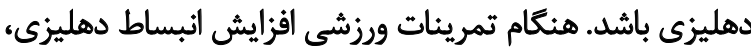

بافت قلب در گروه ديابتى ـ استويا ـ تمرين نسبت به گروه ديابتى -

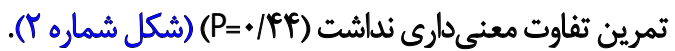

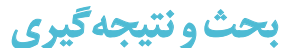

نتايج يُوهش حاضر نشان مى دهد

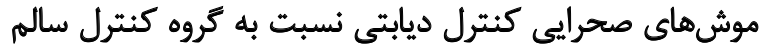

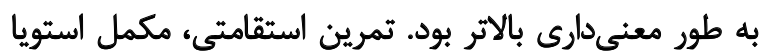

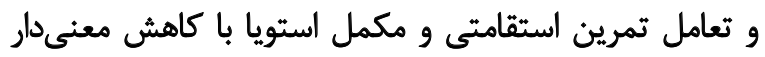

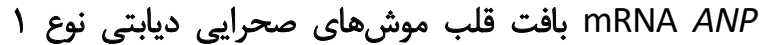

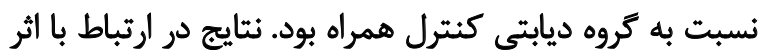

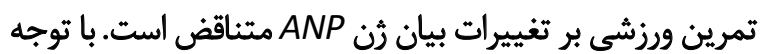


استويا نيز داراى انواع ويتامينها بهخصوص ويتامينهاى آ و ث ثيان

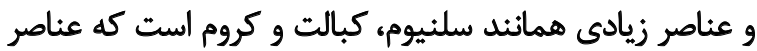

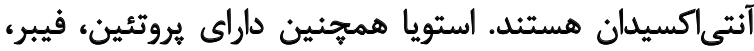

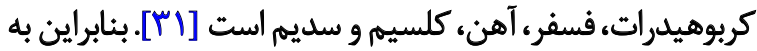

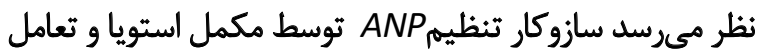

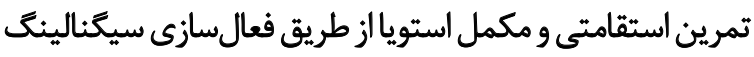

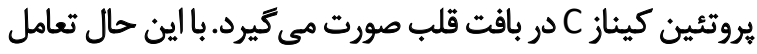

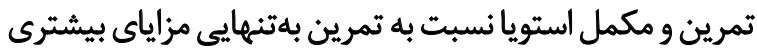

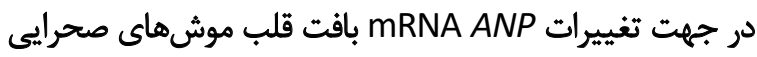

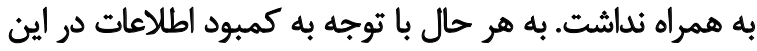
زمينه، به بروهشهاه ندائ بيشترى نياز است.

ديكر يافته هُروهش حاضر نشان مي دهد كه تمرين استقامتي

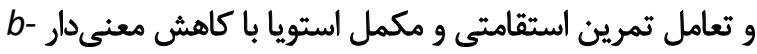
MHC

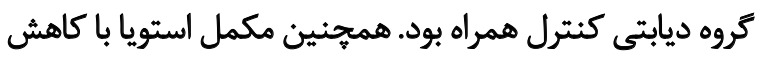

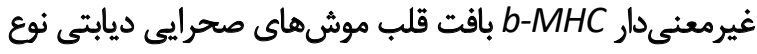

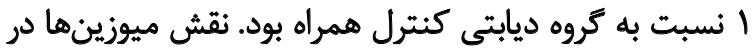

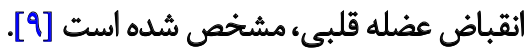

در يبى عوامل استرس زامانند ديابت نوع آلفاء اين بروتئين عمدتاً

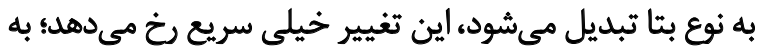

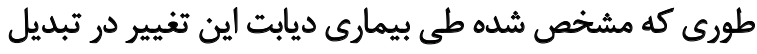

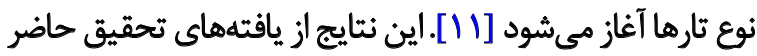

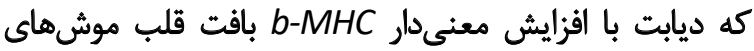

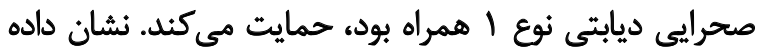

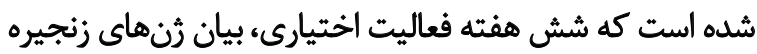

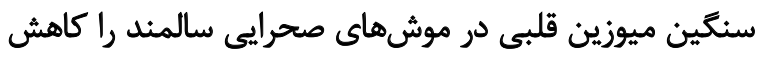

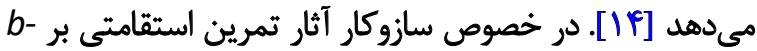

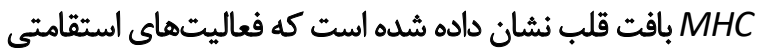

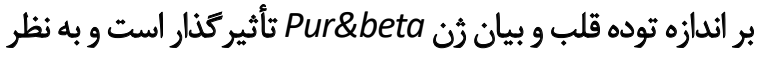
مىرسد كه تغييرات توده قلب در اثر فعاليت استقامتى با با بيان

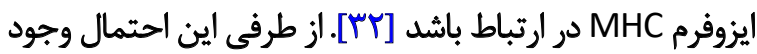

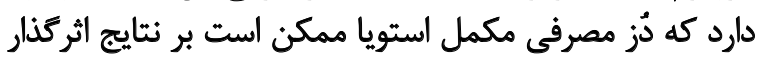

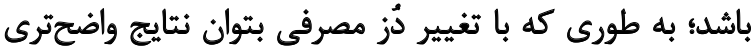

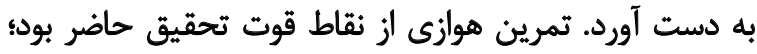

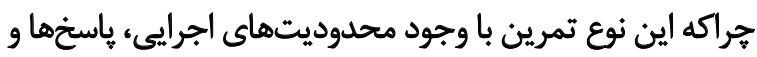

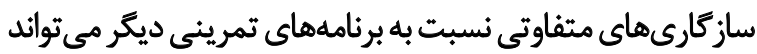

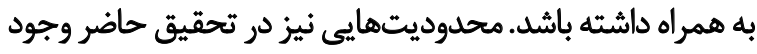

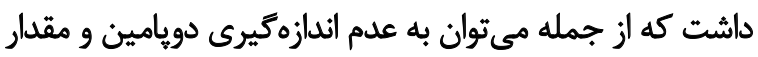

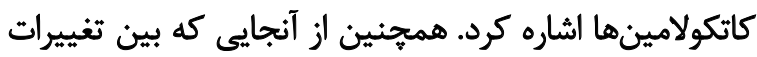

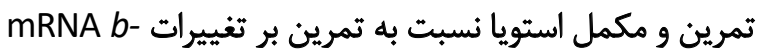

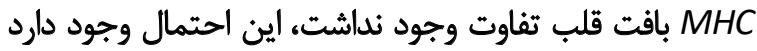

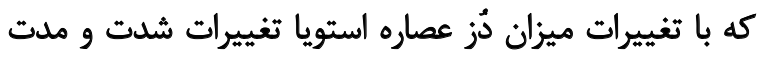

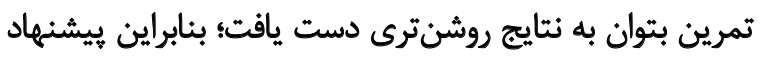

شايد ناشى از حجم خون مركزى باشد كه متناسب با آن فشار

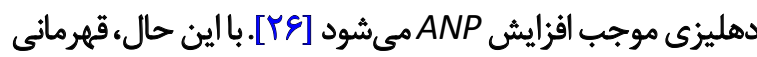

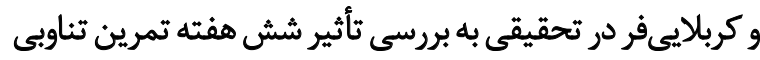

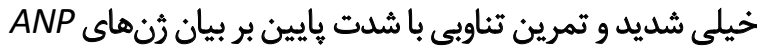

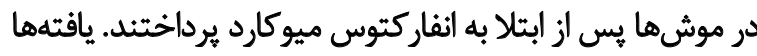

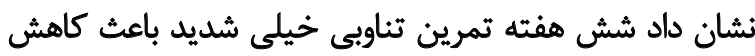

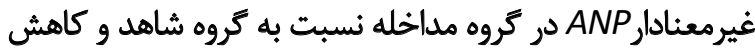

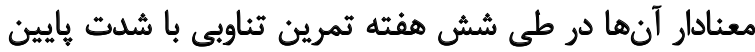

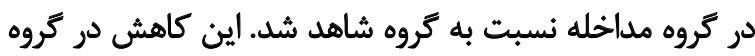

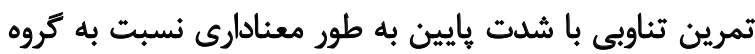

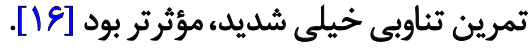

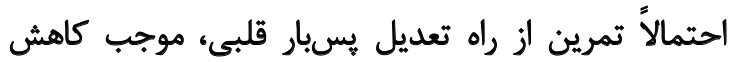

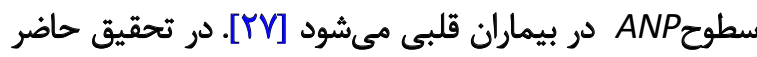

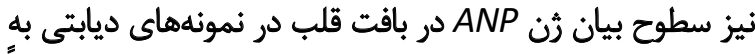

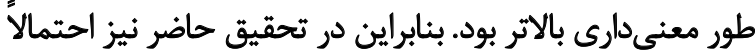

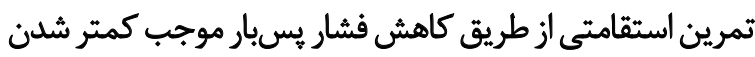

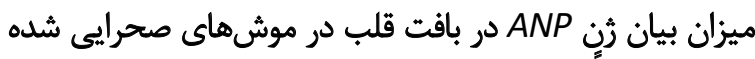

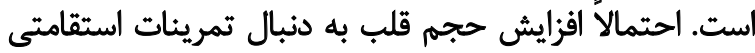

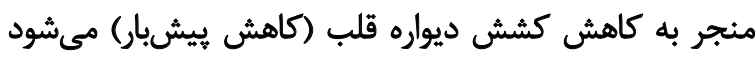

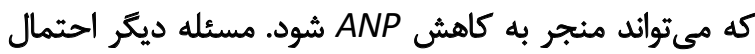

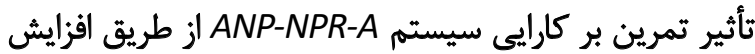

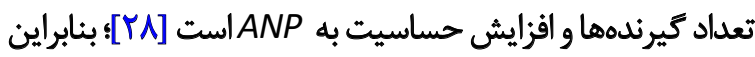

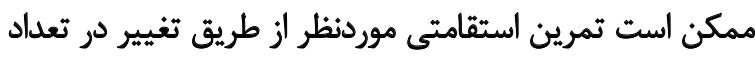

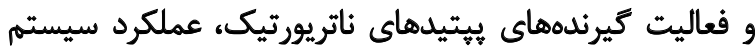
ANP-NPR-A

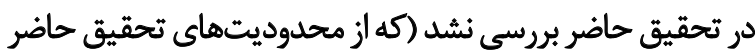

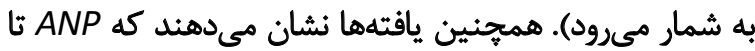

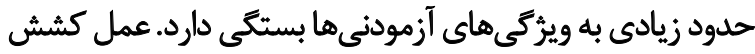

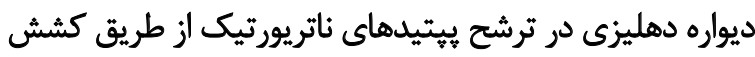

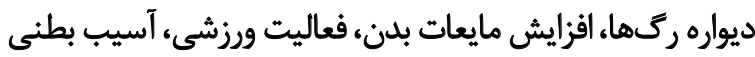

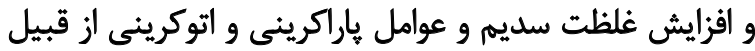

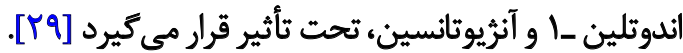
تعادل هموديناميكى در عضله قلب با تغييرات مفيد يُهيتيد

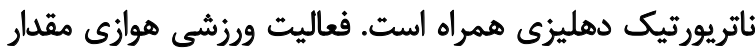

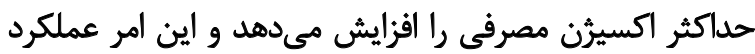

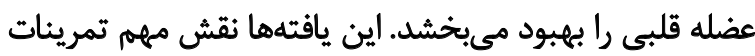

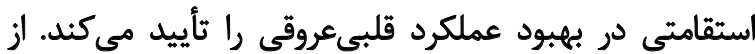

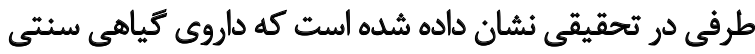

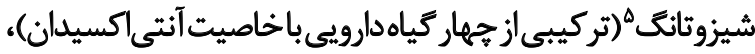

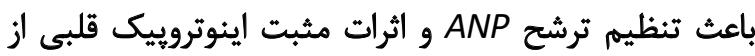

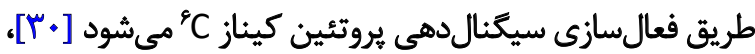

5. Sibjotang

6. Protein kinase 


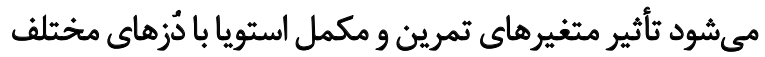

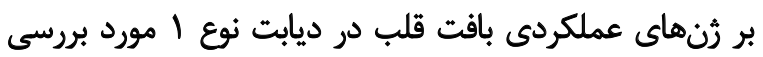

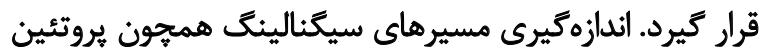

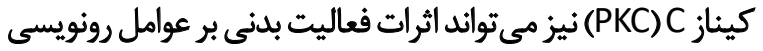

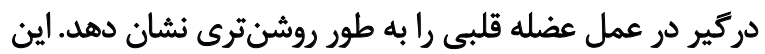

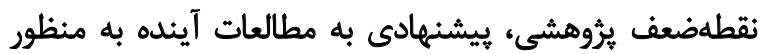

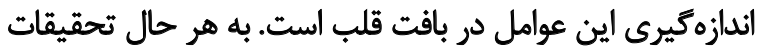
بيشترى در اين زمينه نياز است.

به طور خلاصه، يافتههاى تحقيق حاضر نشان ميدهد كهي

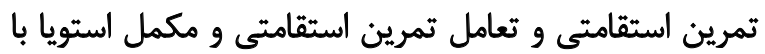
كاهش معنى دار

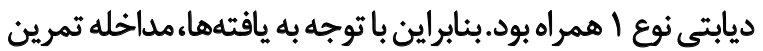

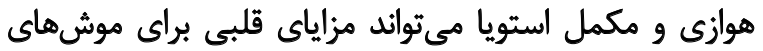
ديابتى نوع ا به همراه داشته باشد.

مالاحظاث أخاقي

$$
\text { بيروى از اصول اخلاق يثوهش }
$$

اين مطالعه توسط كميته اخلاق دانشعاه آزاد اسلامى مرودشت با شماره IR.IAU.M.REC.1399.015 تصويب شده است.

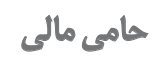

اين مقاله بركرفته از رساله دكترى فيزيولوريى ورزشى خانم كبرى سليمانى در دانشعاه آزاد اسلامى واحتد فيز آيتالله آملى است

$$
\text { مشاركت نويسند مَّان }
$$

نظارت و روششناسى: آسيه عباسى دالويى؛ روش، تهيه

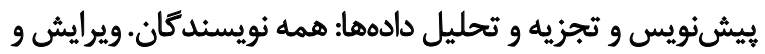
بررسى: كبرى سليمانى، على رضا برارى و ايوب سعيدى نهان.

$$
\text { ت تعارض مناقع }
$$

بنابر اظهار هيجّونه تعارض منافعى در اجراى اين يثوهش

وجود نداشته است.

$$
\text { تشكر و قمدراني }
$$

نويسندكان از همكارى دانشكده تربيتبدنى و علوم ورزشى آني

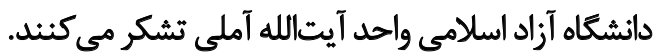




\section{References}

[1] Song W, Wang $\mathrm{H}, \mathrm{Wu} \mathrm{Q}$. Atrial natriuretic peptide in cardiovascular biology and disease (NPPA). Gene. 2015; 569(1):1-6. [DOI:10.1016/j.gene.2015.06.029] [PMID] [PMCID]

[2] Rubattu S, Sciarretta S, Valenti V, Stanzione R, Volpe M. Natriuretic peptides: An update on bioactivity, potential therapeutic use, and implication in cardiovascular diseases. Am J Hypertens. 2008; 21(7):733-41. [DOI:10.1038/ajh.2008.174] [PMID]

[3] Schlueter N, de Sterke A, Willmes DM, Spranger J, Jordan J, Birkenfeld AL. Metabolic actions of natriuretic peptides and therapeutic potential in the metabolic syndrome. Pharmacol Ther. 2014; 144(1):12-27. [DOI:10.1016/j.pharmthera.2014.04.007] [PMID]

[4] Theilade S, Hansen TW, Goetze JP, Rossing P. Increased plasma concentrations of midregional proatrial natriuretic Peptide is associated with risk of cardiorenal dysfunction in type 1 diabetes. Am J Hypertens. 2015; 28(6):772-9. [DOI:10.1093/ajh/hpu227] [PMID]

[5] McKenna K, Smith D, Sherlock M, Moore K, O'Brien E, Tormey $\mathrm{W}$, et al. Elevated plasma concentrations of atrial and brain natriuretic peptide in type 1 diabetic subjects. Ir J Med Sci. 2005; 174(3):53-7. [DOI:10.1007/BF03169149] [PMID]

[6] Lauridsen BK, Iversen K, Hunter I, Bay M, Kirk V, Nielsen OW, et al. ProANP plasma measurement predicts all-cause mortality in acutely hospitalised patients: A cohort study. BMJ Open. 2013; 3(11):e003288. [DOI:10.1136/bmjopen-2013-003288] [PMID] [PMCID]

[7] Bosselmann H, Egstrup M, Rossing K, Gustafsson I, Gustafsson $\mathrm{F}$, Tonder $\mathrm{N}$, et al. Prognostic significance of cardiovascular biomarkers and renal dysfunction in outpatients with systolic heart failure: A long-term follow-up study. Int J Cardiol. 2013; 170(2):202-7. [DOI:10.1016/j.ijcard.2013.10.064] [PMID]

[8] Sabatine MS, Morrow DA, de Lemos JA, Omland T, Sloan S, Jarolim $P$, et al. Evaluation of multiple biomarkers of cardiovascular stress for risk prediction and guiding medical therapy in patients with stable coronary disease. Circulation. 2012; 125(2):233-40. [DOI:10.1161/CIRCULATIONAHA.111.063842] [PMID] [PMCID]

[9] Kolomeisky AB, Fisher ME. Molecular motors: A theorist's perspective. Annu Rev Phys Chem. 2007; 58:675-95. [DOl:10.1146/ annurev.physchem.58.032806.104532] [PMID]

[10] Herron TJ, Korte FS, McDonald KS. Loaded shortening and power output in cardiac myocytes are dependent on myosin heavy chain isoform expression. Am J Physiol Heart Circ Physiol. 2001; 281(3):H1217-22. [DOI:10.1152/ajpheart.2001.281.3.H1217] [PMID]

[11] Gupta MP. Factors controlling cardiac myosin-isoform shift during hypertrophy and heart failure. J Mol Cell Cardiol. 2007; 43(4):388403. [DOI:10.1016/j.yjmcc.2007.07.045] [PMID] [PMCID]

[12] Miyata S, Minobe W, Bristow MR, Leinwand LA. Myosin heavy chain isoform expression in the failing and nonfailing human heart. Circ Res. 2000; 86(4):386-90. [DOI:10.1161/01. RES.86.4.386] [PMID]
[13] Chetty T, Shetty V, Fournier PA, Adolfsson P, Jones TW, Davis EA. Exercise management for young people with type 1 diabetes: A structured approach to the exercise consultation. Front Endocrinol (Lausanne). 2019; 10:326. [DOI:10.3389/fendo.2019.00326] [PMID] [PMCID]

[14] Parsaeifar A, Dabidi Roshan V, Mazaheri Z. Cardioprotective effect of voluntary physical activity on changes of doxorubicininduced cardiac myosin heavy chain expression in aging model rats. Stud Med Sci. 2017; 27(10):893-901. [In Persian] http:// umj.umsu.ac.ir/article-1-3555-en.html

[15] Azadmanesh M, Rashidlamir A, Hejazi SM. The effect of eightweek ladder-climbing exercise on the Atrial Natriuretic Peptide (ANP) gene expression in the heart tissue of Wistar male rats. EBNESINA. 2019; 21(1):20-5. [In Persian] http://ebnesina. ajaums.ac.ir/article-1-582-en.html

[16] Ghahremani M, Karbalaeifar S. Effect of interval training intensity on ANP and BNP gene expression levels after myocardial infarction. Sport Physiol. 2018; 9(36):159-72. [In Persian] https:// spj.ssrc.ac.ir/article_1110_en.html

[17] Agarwal V, Kochhar A, Sachdeva R. Sensory and nutritional evaluation of sweet cereal products prepared using stevia powder for diabetics. Stud Ethno-Med. 2009; 3(2):93-8. [DOI:10.108 0/09735070.2009.11886344]

[18] Chatsudthipong V, Muanprasat C. Stevioside and related compounds: Therapeutic benefits beyond sweetness. Pharmacol Ther. 2009; 121(1):41-54. [DOI:10.1016/j. pharmthera.2008.09.007] [PMID]

[19] Ahmad U, Ahmad RS. Anti-diabetic property of aqueous extract of Stevia rebaudiana Bertoni leaves in Streptozotocin-induced diabetes in albino rats. BMC Complement Altern Med. 2018; 18(1):179. [DOI:10.1186/s12906-018-2245-2] [PMID] [PMCID]

[20] Williams JE, Helsel B, Nelson B, Eke R. Exercise considerations for type 1 and type 2 diabetes. ACSM's Health Fitness J. 2018; 22(1):10-6. [DOI:10.1249/FIT.00000000000000359]

[21] Colberg SR, Laan R, Dassau E, Kerr D. Physical activity and type 1 diabetes: Time for a rewire? J Diabetes Sci Technol. 2015; 9(3):609-18. [DOI:10.1177/1932296814566231] [PMID] [PMCID]

[22] Akbarzadeh S, Barghahi A, Rahbar AR, Daneshi A, Najafpour Bushehri S, Pourkhalili Kh, et al. The effects of aqueous extract of stevia plant (Stevia rebaudiana) on serum concentration of vaspin and Angiopoietin-like Protein-3 in streptozotocin induced diabetic rats. Iran South Med J. 2015; 18(2):239-49. [In Persian] http://ismj.bpums.ac.ir/article-1-669-en.html

[23] Raha D, Tortorella C, Neri G, Prasad A, Raza B, Raskar R, et al. Atrial natriuretic peptide enhances cortisol secretion from guinea-pig adrenal gland: Evidence for an indirect paracrine mechanism probably involving the local release of medullary catecholamines. Int J Mol Med. 2006; 17(4):633-6. [DOI:10.3892/ ijmm.17.4.633] [PMID]

[24] Vogelsang TW, Yoshiga CC, Højgaard M, Kjaer A, Warberg J, Secher $\mathrm{NH}$, et al. The plasma atrial natriuretic peptide response to arm and leg exercise in humans: Effect of posture. Exp Physiol. 2006; 91(4):765-71. [DOI:10.1113/expphysiol.2006.033357] [PMID] 
[25] Bentzen H, Pedersen RS, Nyvad O, Pedersen EB. Influence of training habits on exercise-induced changes in plasma atrial and brain natriuretic peptide and urinary excretion of aquaporin-2 in healthy man. Scand J Clin Lab Invest. 2002; 62(7):541-51. [DOI:1 0.1080/003655102321004567] [PMID]

[26] Niessner A, Ziegler S, Slany J, Billensteiner E, Woloszczuk W, Geyer $\mathrm{G}$. Increases in plasma levels of atrial and brain natriuretic peptides after running a marathon: Are their effects partly counterbalanced by adrenocortical steroids? Eur J Endocrinol. 2003; 149(6):555-9. [DOI:10.1530/eje.0.1490555] [PMID]

[27] Sheikhani Shahin H, Babaee Bigi MA, Aslani A, Daryanoosh F. Effect of professional exercises on brain natriuretic peptide. Int Cardiovasc Res J. 2009; 3(4):e67880. https://sites.kowsarpub. com/ircrj/articles/67880.html

[28] Suda K, Hagiwara H, Kotani Y, Kato K, Sasaki M, Izawa T, et al. Effect of exercise training on ANP receptors. Res Commun Mol Pathol Pharmacol. 2000; 108(3-4):227-35. [PMID]

[29] Wisén AG, Ekberg K, Wohlfart B, Ekman R, Westrin Å. Plasma ANP and BNP during exercise in patients with major depressive disorder and in healthy controls. J Affect Disord. 2011; 129(13):371-5. [DOI:10.1016/j.jad.2010.09.002] [PMID]

[30] Kwon OJ, Oh HC, Lee YJ, Kim HY, Tan R, Kang DG, et al. Sibjotang increases atrial natriuretic peptide secretion in beating rabbit atria. Evid Based Complement Alternat Med. 2015; 2015:268643. [DOI:10.1155/2015/268643] [PMID] [PMCID]

[31] Tavarini, S, Angelini LG. Stevia rebaudiana Bertoni as a source of bioactive compounds: The effect of harvest time, experimental site and crop age on steviol glycoside content and antioxidant properties. J Sci Food Agric. 2013; 93(9):2121-9. [DOI:10.1002/ jsfa.6016] [PMID]

[32] Fathi $M$, Aberon $S$. The effect of endurance activity on left ventricle Pur $\beta$ Gene expressionin Wistar male rat. Sci J Ilam Univ Med Sci. 2016; 23(6):74-84. [In Persian] http://sjimu.medilam. ac.ir/article-1-2564-fa.html 